\title{
UN DIBUJO DEL MONUMENTO DE LA CATEDRAL DE SEVILLA POR LUCAS VALDÉS
}

\author{
POR Alfredo J. Morales
}

Del monumento de la Catedral de Sevilla se tenía un dibujo de fines del siglo XVI y el grabado abierto por Bouttats, en 1737, a partir del dibujo de Domingo Martínez. En el presente rrabajo se da a conocer el firmado por Lucas Valdés en 1695, tras las reforma a que dicha arquitectura temporal fue sometida entre 1688 y 1689 , y que pudo servir de modelo al último de los anteriormente citados. Su finalidad era servir de base a un grabado que pretendía hacer abrir en Roma el canónigo don Luis Federigui. Así lo expresaba en una carta que, desde la Ciudad Etema, dirigió al también canónigo sevillano don Juan de Loaysa.

Previously known drawings of the "Monumento" of Seville Cathedral are one from the end of the 16th century and a 1737 engraving by Bouttats from a drawing by Domingo Martínez. This paper presents a drawing signed by Lucas Valdés in 1695, after the alterations carried out on the temporary structure between 1688 and 1689 , and which may have served as a basis for Martínez's sketch. It was drawn as a model for an engraving which the canon Don Luis Federigui intended to have made in Rome. This desire of his is expressed in a letter sent from the Eternal City to his fellow Sevillian canon, Don Juan de Loaysa.

Del esplendor que, en tiempos pasados, alcanzaban las celebraciones de la Semana Santa en la catedral sevillana dan testimonio algunas de las principales piezas de su mobiliario litúrgico. Es el caso del Candelero de Tinieblas, del Cirio Pascual y, sobre todo, del Monumento Eucarístico. De las tres, sólo el segundo, aunque alterada su tradicional fisonomía y reducidas sus proporciones y ornamentación, continúa en uso ${ }^{1}$. Las reformas litúrgicas, en relación con el primero,

1. Para comprobar las diferencias entre el antiguo Cirio Pascual y el actualmente en uso, contémplese el dibujo del mismo que, aún exagerado en su escala, realiź David Roberts en 1837 y 
y el elevado costo de las operaciones de montaje y desmontaje del segundo, unido a su mal estado de conservación, han hecho de aquel un objeto de museo y de este una pieza de almacén. Desde que al "magestuoso y portentoso Monumento de Sevilla" se le dio tan triste destino, las funciones para las que este fue creado las viene cumpliendo el altar de plata del Corpus Christi. Sin embargo, esto no ha significado, por fortuna, el olvido de la imponente máquina que anualmente se erigía en el trascoro de la catedral con motivo de la Semana Santa. Muy al contrario. Ha sido en los últimos años, y coincidiendo con su falta de uso, cuando se ha despertado la curiosidad de los investigadores y cuando se han elaborado, en torno al mismo, los principales estudios. Gracias a ellos es hoy posible saber, con fiabilidad, su historia y el nombre de sus creadores, especialmente lo referente a su construcción en el siglo XVI y a su ampliación y reforma a fines del seiscientos ${ }^{2}$. Con respecto a la fisonomía que presentaba en los últimos años de vida se tenían distintas fotografías de mediados del presente siglo, conociéndose su imagen de comienzos del setecientos gracias al grabado abierto en Amberes por Pedro Baltasar Bouttats siguiendo un dibujo de Domingo Martínez ${ }^{3}$. A partir de ahora, a este reducido corpus gráfico debe anteponerse el dibujo que ha dado origen a estos comentarios.

Dicha representación había pasado desapercibida hasta el momento presente, a pesar de estar colgada en uno de los muros de la, hasta hace poco tiempo, sala de investigadores del Archivo de la Catedral de Sevilla ${ }^{4}$. Corresponde a un dibujo sobre papel entelado, realizado a tinta y coloreado, que aparece firmado y fechado "D. Lucas de Valdes Hispalensis pinxit. Anno 1695" 5 . En el mismo, el monumento se representa en su habitual emplazamiento del trascoro, visto en perspectiva y por su frente de levante. Tal circunstancia se deduce de la posición de las imágenes que centran los cuerpos segundo -Cristo Redentor-, tercero -

litografió W. Gauci. Al respecto, véase PORTUS, Javier: "Catálogo", en Iconografía de Sevilla, Madrid, 1991, pág. 281. Con relación a la ornamentación y programa iconográfico de dicho objeto litúrgico, consúltese SERRERA, Juan Miguel: "Pinturas y pintores del siglo XVI en la Catedral de Sevilla", en La Catedral de Sevilla, Sevilla, 1985, pág. 358.

2. Véase, respectivamente, LLEÓ CAÑAL, Vicente: "El Monumento de la Catedral de Sevilla durante el siglo XVI", en Archivo Hispalense, 1976, n. 180 y GARCÍA HERNÁNDEZ, José Antonio: "Las imágenes escultóricas del Monumento de la Catedral de Sevilla en la renovación de 16881689", en Atrio, 1989, n. ${ }^{2} 1$.

3. Dicho grabado fue dado a conocer por SORO CAÑAS, Salud: Domingo Martinez, Arte Hispalense, n.. 31 . Sevilla, 1982, págs. 109-110. El mismo ha sido reproducido, precisando el nombre del grabador y transcribiendo la leyenda que figura en la cartela inferior por PORTUS, Javier: "Catálogo. La ciudad efímera", en Iconografia de Sevilla 1650-1790, Madrid, 1989, pág. 259.

4. Durante el año 1992 el Archivo de la Catedral de Sevilla ha sido trasladado a su nuevo emplazamiento de las naves del Patio de los Naranjos, compartiendo sede con la Biblioteca Capitular y Colombina.

5. Realizado en tinta y aguadas gris, roja, azul y dorada. Mide 2,57 x 1,69 metros. 
Cristo atado a la columna- y ático -Calvario-, por más que en el dibujo no figure, habida cuenta la grandiosidad del monumento, elemento alguno de referencia, que sirva de fondo a la composición. Tal visión es, además de lógica, la tradicional, por cuanto corresponde a la más completa y precisa, siendo prueba de ello su empleo en el dibujo del monumento de 1594, correspondiente al libro de Messía de la Cerda Discursos Festivos, y en el grabado de Bouttats, antes citado, además de repetirse por Valdés Leal al grabar el triunfo a San Fernando, erigido en 1671 con motivo de su canonización, incluido en la obra de Torre Farfán Fiestas de Sevilla. ${ }^{6}$.

El "portentoso" aparato eucarístico figura rodeado por distintos hacheros y enmarcado por los cuatro pilares que determinan el tramo segundo de la nave central del templo, espacio que resulta delimitado con barandas de hierro. Los citados pilares se cubren con paños rojos, enriquecidos con flecos y galones dorados, que deben corresponder a los de terciopelo que, regalados por el Consulado de Cargadores a Indias, se estrenaron en $1694^{7}$. Idénticas colgaduras sirven para cubrir la tribuna y la Puerta de la Asunción, al fondo de la imagen. Con objeto de completar la representación gráfica del monumento, se han incluido en los ángulos inferiores del dibujo una semisección de su estructura, tomada en sentido este-oeste, y la planta del cuerpo inferior. Ambas se acompañan de escalas, indicándose en la de esta última, sobre la firma del autor y la fecha de realización de la obra, que corresponde a un "Pitipie de 6 varas". A modo de complemento, se incluye al centro de la zona baja del dibujo una cartela, rodeada por roleos y elementos vegetales, con una muy deteriorada inscripción latina, encabezada por el nombre del Papa Benedicto XII ${ }^{8}$.

En razón de la fecha de ejecución del dibujo, resulta evidente que es posterior a la renovación a la que fue sometido el monumento entre 1688 y 1689 . Cabe, además, considerarlo como una consecuencia o complemento del texto redactado en 1692, relativo a las operaciones de su montaje y desmontaje y en el que se incorporan tres elementales croquis, correspondientes al plano de cornisas

6. Veánse MESSIA DE LA CERDA, Reyes: Discursos festivos en que se pone la descripcion del ornato e invenciones que en la fiesta del Sacramento la parrochia collegial y vezinos de Sant Salvador hizieron. Introducción y transcripción por Vicente Lleó Cañal, Madrid, 1985, págs. 14-22. TORRE FARFÁN, Fernando de la: Fiestas de la Santa Iglesia Metropolitana y Patriarcal de Sevilla al nuevo culto del señor rey San Fernando el Tercero de Castilla y León. Sevilla, 1671. Reedición Madrid, 1984 con introducción de Antonio Bonet Correa, págs. 21-122. Sobre el propio triunfo puede también consultarse FERRER GARROFE, Paulina: Bernardo Simón de Pineda. Arquitectura en madera. Arte Hispalense, n. ${ }^{\circledR} 32$, Sevilla, 1982, págs. $72-79$.

7. Cfr. GESTOSO Y PÉREZ, José: Sevilla monumental y artística, Tomo II, Sevilla, 1890, pág. 143.

8. El mal estado de conservación del dibujo impide la lectura de dicha inscripción. No obstante, algunas palabras legibles parecen aludir a la concesión de indulgencias. 
de los respectivos cuerpos 9 . No obstante ello, dicha representación debe vincularse directamente a una carta, fechada en Roma el 13 de febrero de 1695 y en la que Don Luis Federigui, interesado en "dar a conozer algunas de las magnificas obras de nuestra iglesia y entre ellas el Monumento y su fabrica y cantidad de luces y forma en que esta dispuesto", solicitaba a Don Juan de Loaysa que "un buen Pintor ó debujador nos haga un bello dizeño de esta fabrica; pintandolo o debujandolo en un papel en la forma que el esta ensendido y anotando sus cuerpos figuras fabrica y dispossicion porque quiero hazer abrir una bella lamina para que aqui bean lo que es esta fabrica". El escrito continuaba precisando que fuera mejor dibujo que el de la custodia, "que es un borron", que el costo de ejecución del grabado sería menor en Roma y que pensaba hacerlo a su costa ${ }^{10}$. El texto hasta aquí extractado, aunque breve, ofrece información digna de comentario, a la vez que sugiere la relación directa de los personajes citados con diversos dibujos y pinturas conservadas en la catedral sevillana. El primer aspecto a considerar es la respectiva personalidad de remitente y destinatario de la misiva. Aquel, sobrino del Arcediano de Carmona Don Juan Federigui y también canónigo, tras ser nombrado Juez de la Iglesia, pasó a Roma en 1688 para defender los derechos de la catedral sevillana en los distintos pleitos suscitados por el arzobispo Don Jaime Palafox ${ }^{11}$. Es precisamente en relación con esta comisión, como debe interpretarse su afán por divulgar, en sus múltiples aspectos, la grandeza de la catedral sevillana. Si en el caso anterior se trataba del monumento, en otra ocasión debió ser el altar de plata para el Corpus Christi, del que posee la propia catedral una interesante pintura al óleo, atribuida a Lucas Valdés. Pero, aún más. Con su misión en la Ciudad Eterna sobre los pleitos originados por el arzobispo Palafox, deben relacionarse los dibujos conservados en el Archivo de la Catedral de Sevilla, representando el ostensorio antiguo del templo, dos sillones arzobispales, un paso de Virgen, los costaleros que portan la custodia en la procesión del Corpus Christi y las parihuelas destinadas al mismo fin. Algunos de estos dibujos aparecen firmados, curiosamente, por Lucas Val-

9. Al canónigo Juan de Loaysa se atribuye la redacción del manuscrito relativo al montaje y desmontaje del monumento que se conserva en el Archivo de la Catedral de Sevilla. Cfr. RUBIO MERINO, Pedro: Archivo de la Santa Metropolitana y Patriarcal Iglesia Catedral de Sevilla. Inventario General, Madrid, 1987, pág. 177. En relación con dicho texto, véase GARCÍA HERNÁNDEZ, José Antonio: "El montaje del monumento eucarístico de la Catedral de Sevilla en 1692", en Atrio, $1990, \mathrm{n} .{ }^{2} 2$. 296.

10. El texto completo de la carta es transcrito por GESTOSO Y PÉREZ, José: Op. cit., pág.

11. Sobre el canónigo Don Luis Federigui, consúltese MATUTE Y GAVIRIA, Justino: Hijos de Sevilla señalados en santidad, letras, armas, artes o dignidad, Tomo II, Sevilla, 1888, págs. 127-129. 
dés, presentando, además, leyendas en italiano, a excepción del último que la lleva en un latín italianizado ${ }^{12}$.

La personalidad de Don Juan de Loaysa es algo mejor conocida, por cuanto él mismo ofreció un resumen biográfico en sus Memorias sepulcrales de la Santa Iglesia de Sevilla ${ }^{13}$. Siendo prebendado y canónigo de la catedral sevillana desempeñó diversos puestos de responsabilidad, encargándose, junto a Don Justino de Neve, de las fiestas organizadas para celebrar la canonización de San Fernando, especialmente de la ordenación y construcción del triunfo erigido en el trascoro, anteriormente citado. Como mayordomo de la fábrica se ocupó de la renovación a que fue sometido el monumento entre 1688 y 1689 , siendo, como se ha dicho, el posible autor del manuscrito sobre el montaje y desmontaje del mismo, fechado en 1692. Estas circunstancias y su continua preocupación y curiosidad por las antigüedades, la historia y los principales prohombres sevillanos, como prueban sus escritos, además de razones de conocimiento y amistad, fundamentarían la carta de Don Luis Federigui. A su solicitud respondió con prontitud Loaysa, por cuanto el dibujo del monumento aquí estudiado se fecha en el mismo año que la carta. Pese a todo, no parece que la intención de grabarlo se llegara a cumplir, pues la presencia de dicho dibujo en la catedral sevillana prueba que nunca se envió a Roma, ciudad en la que Federigui proyectaba abrir dicho grabado. Tal vez el fallecimiento de éste en abril de 1696, impidiese hacer realidad su proyecto ${ }^{14}$.

Las razones por las que Loaysa acudió a Lucas Valdés para cumplir el encargo son desconocidas. No obstante, pudo influir en la elección la participación del artista -casi un niño-, en las fiestas organizadas con motivo de la canonización de San Fernando y en los grabados del libro de Torre Farfán, a ellas dedicado y anteriormente citado ${ }^{15}$. De igual manera, debió incidir favorablemente la realización, por aquellos años, de los dibujos citados en el Archivo de la Catedral, relacionados con la misión desempeñada en Roma por Federigui. Asimismo, tampoco debió ser ajeno al encargo la asidua dedicación de Valdés a las grandes representaciones de carácter escenográfico, dominadas por los estudios de perspectivas arquitectónicas. Prueba de ello son las pinturas murales que decoran las iglesias sevillanas de San Luis, de la Magdalena -antiguo Convento

12. Dichos dibujos han sido catalogados por LUNA FERNÁNDEZ-ARAMBURU, Rocío y SERRANO BARBERÁN, Concepción: Planos y dibujos del Archivo de la Catedral de Sevilla. (Siglos XVI-XX), Sevilla, 1986, págs. 117, n. 114; pág. 208, n. ${ }^{2} 201$ y 202; pág. 209, n. $.^{\circledR} 204,205$ y 206 , respectivamente. 28-39.

13. El texto del mismo es reproducido por MATUTE Y GAVIRIA, Justino: Op. cit., págs.

14. Cfr. MATUTE Y GAVIRIA, Justino: Op. cit., pág. 129.

15. Véase nota $n . .^{9} 6$. 
de San Pablo- y de los Venerables Sacerdotes, así como dibujos y otras obras de caballete de formato menor, caso de la representación de la Capilla Real ${ }^{16}$. Respecto a su condición de dibujante, no pueden olvidarse los dibujos realizados en 1711, a instancias de Don Manuel Martí y Don Francisco Lelio, sobre el anfiteatro de Itálica, poco tiempo antes de la parcial demolición del edificio, tras acordarse emplear sus materiales en la construcción de un muro que defendiese Sevilla de las arriadas del Guadalquivir ${ }^{17}$. Fue el dominio de la geometría lo que le permitió resolver con extraordinaria habilidad tal tipo de obras, consideradas entre lo mejor de su producción. Por otra parte, fueron sus conocimientos en dicha ciencia los que le llevaron a Cádiz, como profesor de matemáticas del Colegio Naval de dicha ciudad ${ }^{18}$.

De su pericia en tales materias hizo gala Lucas Valdés al dibujar el monumento de la catedral sevillana. En este sentido, el artista puso el mismo empeño en presentar el enmarque arquitectónico que en reproducir los distintos cuerpos y elementos integrantes del "magestuoso" aparato, procurando adoptar, en cada caso, el punto de vista más adecuado. De hecho, la imagen da a entender que el pintor, al copiar del natural, ocupó en el trascoro una posición en alto, tal vez el acceso a los órganos de la catedral o la propia tribuna en que estos se situaban. De ahí que el cuerpo inferior aparezca claramente tomado desde arriba, mientras los dos cuerpos superiores -obviamente en menor medida el central-, se dibujan desde abajo. Es, sin duda, este juego de puntos de vista lo que concede mayor monumentalidad, valga la redundancia, al propio monumento. Pero la búsqueda de tales efectos no significó el descuido o abocetado del dibujo. Este se ha realizado con toda precisión y minuciosidad en sus aspectos lineales, como corresponde a un buen geómetra. Sólo en las aguadas, empleadas para fingir el volumen y la existencia de distintos planos, la técnica es más espontánea y suelta. Especialmente evidentes resultan estas diferencias en la representación de la custodia procesional, situada al centro del cuerpo inferior. El aspecto de la misma hace sospechar que Lucas Valdés se sirviera del grabado al aguafuerte de dicha custodia, realizado por su padre Juan Valdés Leal en 1668, tras las reformas a que fue sometida por Juan de Segura ${ }^{19}$. Posiblemente se trate del mismo

16. Sobre esta pintura puede verse MORALES, Alfredo J.: "Iconografía de la Capilla Real de Sevilla", en Archivo Hispalense, 1989, n. 221.

17. Véase RÍOS, Demetrio de los: Memoria arqueológica-descriptiva del Anfiteatro de Itálica, acompañada del plano y restauración del mismo edificio, Madrid, 1862, pág. 13.

18. Para la biografía y obra de este pintor, véase VALDIVIESO, Enrique: Historia de la pintura sevillana. Siglos XIII al XX, Sevilla, 1986, págs. 283-295.

19. Sobre las reformas a que fue sometida la custodia procesional, consúltese SANZ SERRANO, María Jesús: Juan de Arfe y Villafañe y la custodia de Sevilla. Arte Hispalense, n. 17. Sevilla, 1978, págs. 106-111. Los cuatro grabados -conjunto, cuerpo inferior, cuerpo intermedio y cuerpo 
grabado al que Don Luis Federigui calificaba en su carta de "borron", en clara referencia a la falta de nitidez que presenta la custodia, sobre todo por los cortinajes incorporados por Valdés Leal para servirle de marco. El uso del grabado paterno resulta más evidente si se compara esta imagen de la custodia con la que el propio Lucas Valdés dibujará unos años más tarde y que grabaría, en 1703 y para la catedral sevillana, Benedicto Farial ${ }^{20}$.

Sin embargo, no fue esta la única idea que el hijo tomó del padre. De hecho, la propia composición del dibujo del monumento y su enmarque, aunque no el punto de vista, remiten al grabado de Valdés Leal sobre el triunfo erigido a San Fernando, varias veces ya citado, que ilustra el también aludido libro de Torre Farfán Fiestas de Sevilla. Una dependencia similar puede establecerse entre la cartela que ocupa la zona inferior del dibujo del monumento, respecto a la tarja empleada por Juan de Valdés en el grabado titulado "Puerta Principal de la Iglesia que sale a Gradas enfrente del Triunfo", del mismo libro. Por otra parte, dicha cartela, aunque más recargada y con roleos más carnosos, recuerda las pintadas por Lucas Valdés en las distintas escenas que, fingiendo ser tapices, decoran la nave de la Iglesia de los Venerables Sacerdotes.

Como última reflexión sobre el dibujo de Lucas Valdés cabe plantear su utilización por Domingo Martínez en su diseño de 1737 sobre el propio monumento, después grabado por Bouttats. Las coincidencias en cuanto a esquema y puntos de vista de la representación son tan evidentes que resulta imposible considerar que Martínez no copiara a Valdés. De hecho, el primero parece haberse limitado a reproducir el dibujo de este último, simplificando o suprimiendo algunos elementos, además de incorporar otros nuevos de carácter barroco y teatral. Entre los eliminados se encuentran los hacheros que Valdés sitúa en las gradas de acceso al primer cuerpo, lugar en el que Martínez ha dispuesto las figuras arrodilladas de unos clérigos, personajes que contribuyen a magnificar la escala del monumento. También han desaparecido la sección y planta del mismo que ocupaban los ángulos inferiores en el primer dibujo, las colgaduras que revestían los pilares y muro del templo, así como los roleos y temas ornamentales que cubrían los elementos arquitectónicos del propio monumento. Por el contrario, la representación la ha enriquecido Martínez al magnificar la arquitectura que le sirve de marco, al acrecentar y barroquizar la cartela de la zona inferior $\mathrm{y}$, sobre todo, al incorporar una movida orla de ángeles que portan diseños de las plantas del propio monumento y de la custodia, filacterias con

superior-, de Juan de Valdés Leal sobre a custodia de la catedral de Sevilla son reproducidos en PORTUS, Javier: "Catálogo. La ciudad efímera". Op. cit., págs. 256 y 257.

20. El grabado de la custodia, realizado por Benedicto Farial a partir del dibujo de Lucas Valdés, es reproducido y estudiado por PORTUS, Javier: "Catálogo. La ciudad efímera". Op. cit., págs. 258 y 259. 
leyendas, escudos y atributos eucarísticos. Pero ni siquiera la presencia de este peculiar enmarque es original, puesto que la idea procede del varias veces aludido grabado de Juan de Valdés Leal sobre el triunfo de San Fernando en las fiestas de su canonización.

Con todo, el dibujo de Domingo Martínez sí se trasladó al grabado y tuvo cierta difusión, mientras el de Lucas Valdés, quedó olvidado en una dependencia de la catedral sevillana. Tal vez, las características técnicas de su representación -exceso de detalle en lo ornamental y empleo del color-, dificultaran su traslado al grabado y llevaran a su olvido. Sería por ello que cuando, años más tarde, la catedral sevillana decidió contar con una imagen grabada de tan "magestuoso y portentoso monumento", se vio obligada a encargar un nuevo dibujo del mismo. 


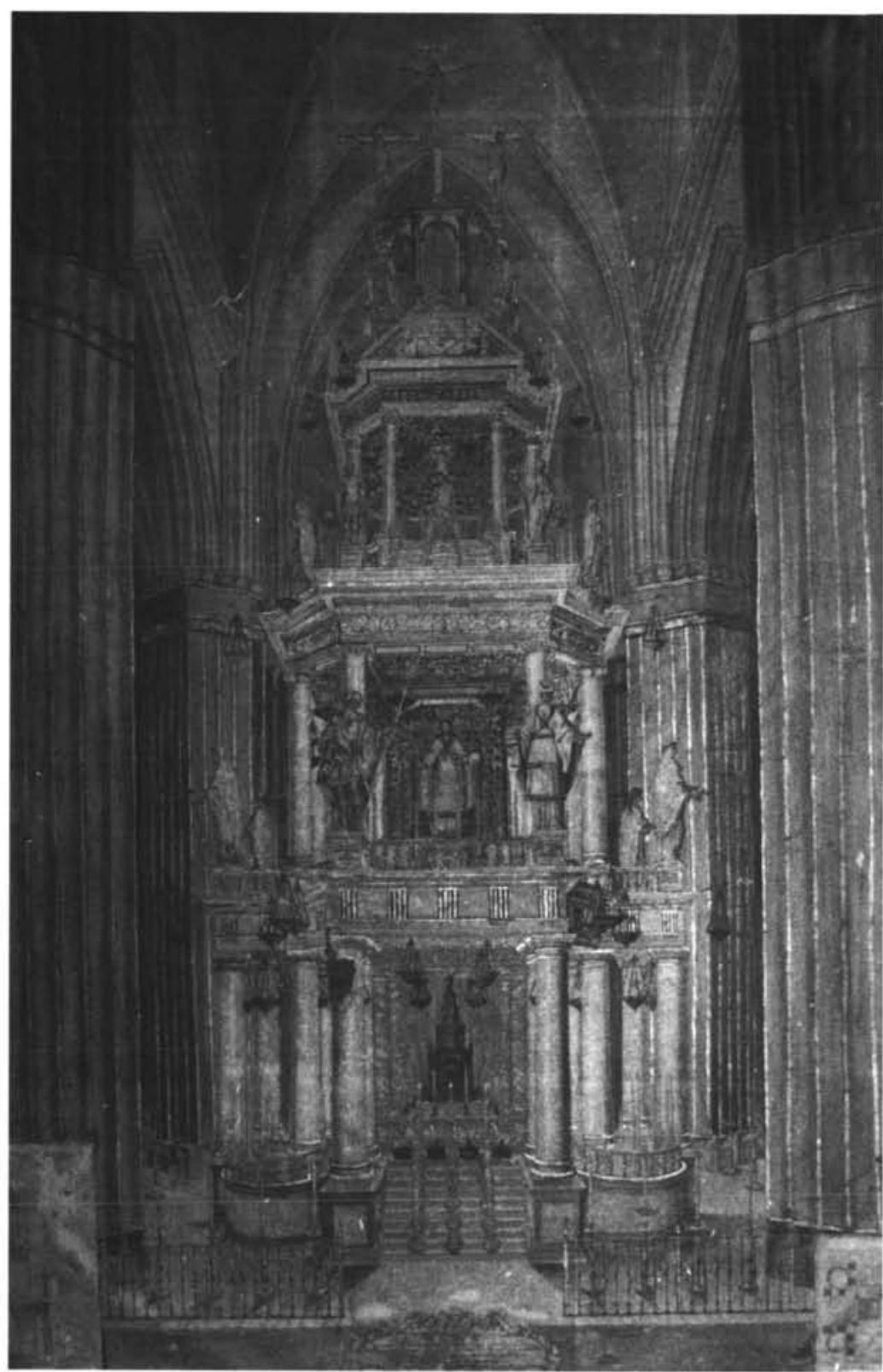

Fig. 1.

Lucas Valdés. El Monumento de la Catedral de Sevilla. 1695 


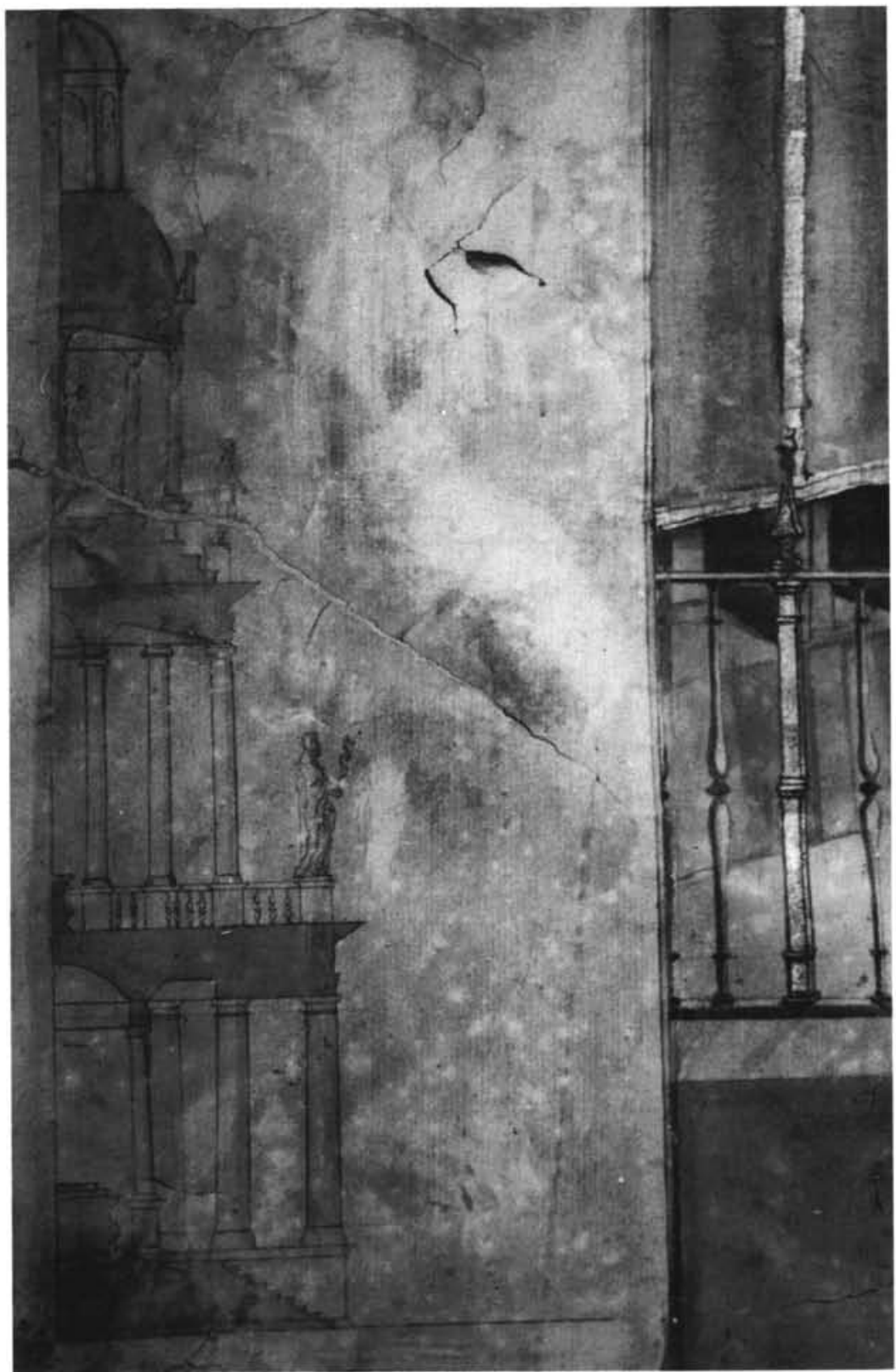

Fig. 2 .

Lucas Valdés. El Monumento de la Catedral de Sevilla. Sección. 1695 


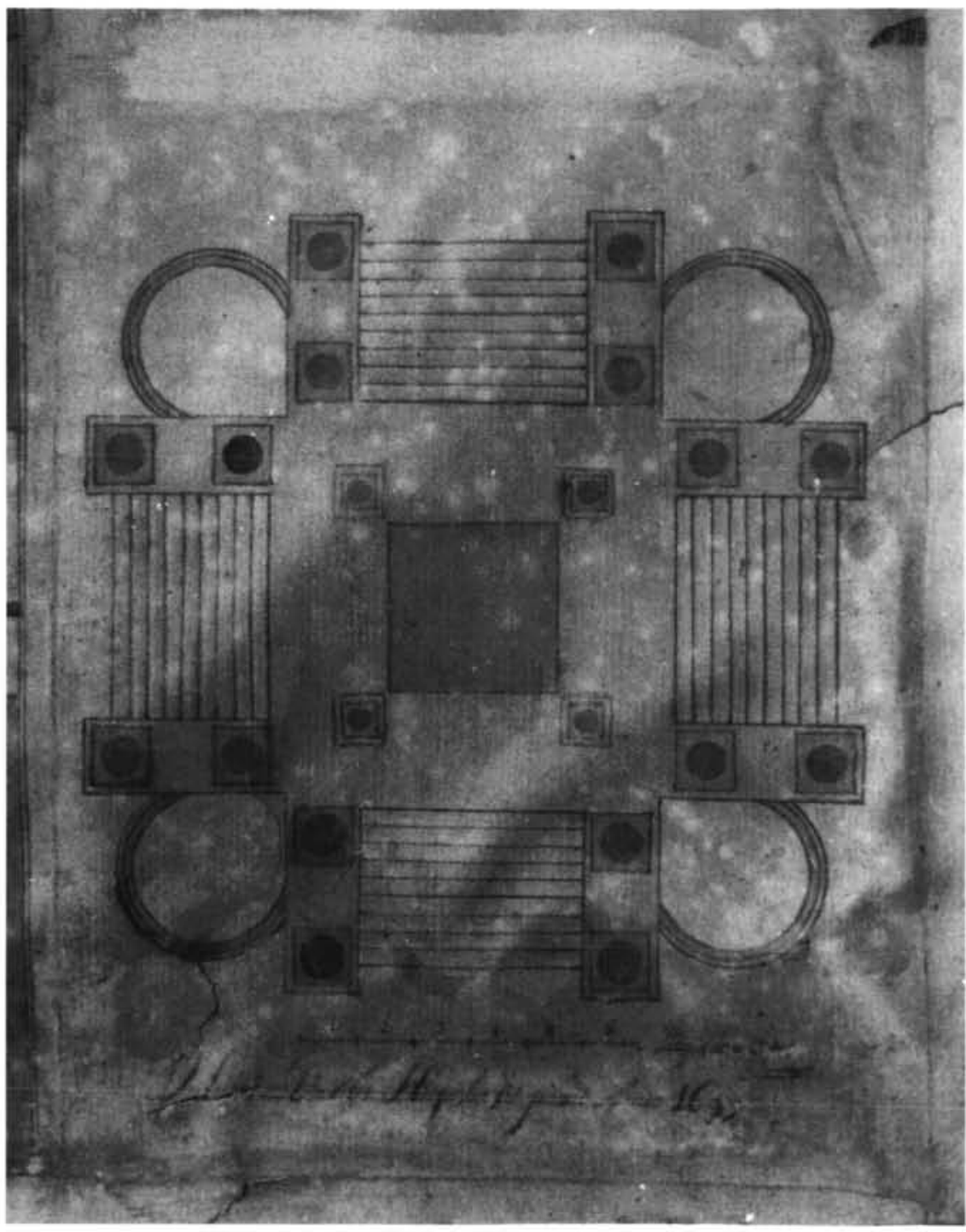

Fig. 3.

Lucas Valdés. El Monumento de la Catedral de Sevilla. Planta. 1695 